J. A. M. MERCER, C. M. COHEN, S. R. SHUKEN, A. M. WAGNER, M. W. SMith, F. R. MOSS, III, M. D. SMith, R. VAHALA, A. GONZALEZ-MARTineZ,* S. G. BOXER,* N. Z. BURNS* (STANFORD UNIVERSITY, USA AND AALTO UNIVERSITY, FINLAND)

Chemical Synthesis and Self-Assembly of a Ladderane Phospholipid

J. Am. Chem. Soc. 2016, 138, 15845-15848.

\title{
Total Synthesis of a Ladderane Phospholipid
}

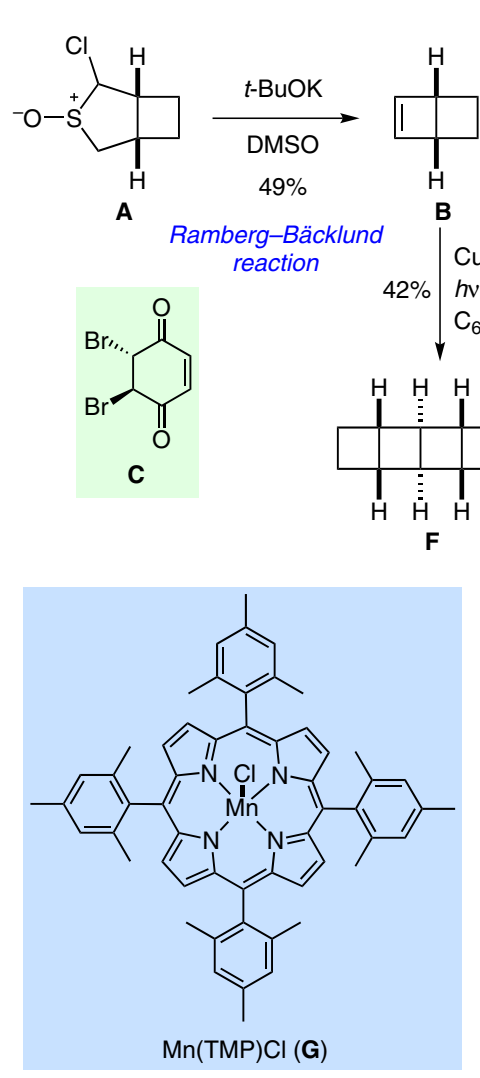

1. C, $h v(350 \mathrm{~nm})$
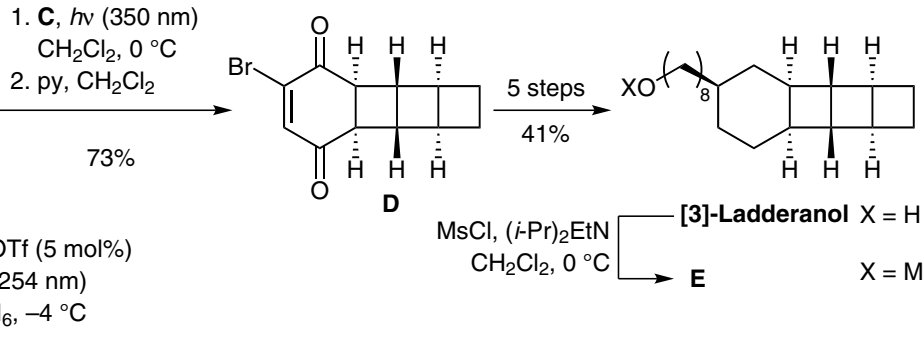

D

$\mathrm{MsCl},(i-\mathrm{Pr})_{2} \mathrm{EtN}$
$\mathrm{CH}_{2} \mathrm{Cl}_{2}, 0^{\circ} \mathrm{C}$

[3]-Ladderanol $\mathrm{X}=\mathrm{H}$

E

$X=M s$

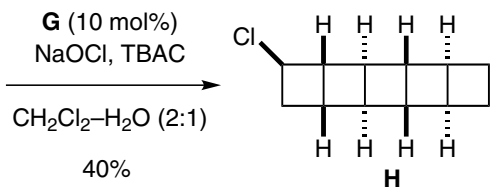

$t$-BuOK
$\begin{gathered}\text { THF, } 0 \text { to } 500^{\circ} \mathrm{C} \\ 91 \%\end{gathered}$

$\mathrm{Cu}(\mathrm{MeCN}){ }_{4} \mathrm{PF}_{6}(10 \mathrm{~mol} \%)$ (R)-DM-SEGPHOS (11 mol\%) $\mathrm{B}_{2} \mathrm{pin}_{2}, t-\mathrm{BuONa}, \mathrm{MeOH}$

\section{THF, $-78{ }^{\circ} \mathrm{C}$}

$95 \%, 90 \%$ ee

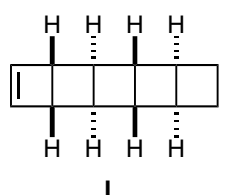

Category

Synthesis of Natural

Products and

Potential Drugs

\section{Key words}

[2+2] cycloaddition

[5]-ladderanoic acid

[3]-ladderanol

ladderane

phospholipids

Ramberg-Bäcklund reaction

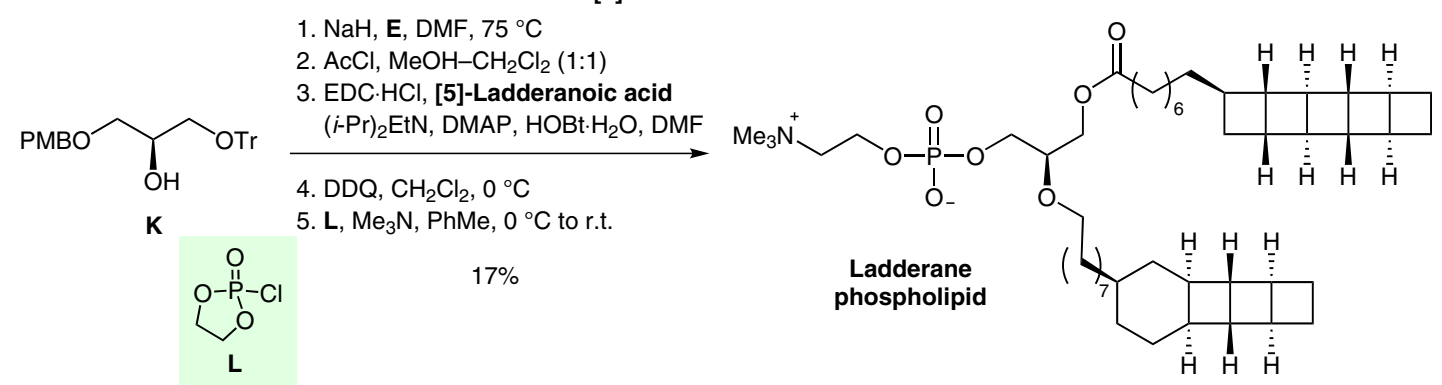

Significance: Gonzalez-Martinez, Boxer, Burns and co-workers report an impressive total synthesis of a ladderane phospholipid based on strategic $[2+2]$ cycloadditions of bicyclohexene $\mathbf{B}$, which is obtained by means of a Ramberg-Bäcklund ring contraction of sulfoxide $\mathbf{A}$.

SYNFACTS Contributors: Erick M. Carreira, Leonardo J. Nannini Synfacts 2017, 13(02), 0117 Published online: 18.01.2017 Dol: 10.1055/s-0036-1589874; Reg-No.: C08416SF
Comment: Bicyclohexene B irradiated in the presence of CuOTf gave pentacycle $\mathbf{F}$, which was subjected to an oxidative chlorination-elimination sequence to give cyclobutene I. Enantioselective hydroboration and four further steps yielded [5]-ladderanoic acid. 